\title{
Aprendizagem de Português como Língua Adicional em um projeto colaborativo online
}

\author{
Nancibel Webber Gonzalez \\ Universidade Federal do Rio Grande do Sul \\ nancibelw@gmail.com \\ Margarete Schlatter \\ Universidade Federal do Rio Grande do Sul \\ margarete.schlatter@gmail.com
}

\section{Resumo}

O objetivo do presente artigo é analisar a relação entre o desenvolvimento de um projeto de aprendizagem de português como língua adicional a distância e a construção de uma comunidade de aprendizagem colaborativa online pelos participantes. O Curso de Espanhol-Português para Intercâmbio, CepiPortuguês, é um curso online de preparação sociolinguística e cultural para o intercâmbio acadêmico entre estudantes de universidades latino-americanas. Fundamentado na perspectiva de projetos de aprendizagem e trabalho colaborativo, o estudo analisa as ações e interações ocorridas nas plataformas tecnológicas utilizadas pelos participantes (Moodle, Skype e Facebook). A análise descreve o modo como foi configurado o trabalho conjunto de um grupo de estudantes para desenvolver o projeto, identificando as oportunidades de aprendizagem no uso da língua portuguesa criadas por intermédio da participação na construção colaborativa de um evento no Facebook.

Palavras-chave: Projetos de aprendizagem. Ensino online. Português como língua adicional. Trabalho colaborativo.

\begin{abstract}
The purpose of this article is to analyze the relation between the development of a learning project in an online Portuguese as additional language course and the participants' building of an online collaborative community. CEPIPortuguese is an online course designed to prepare undergraduate students sociolinguistically and culturally for academic exchange in Latin American universities. Based on the perspective of project based learning and
\end{abstract}


collaborative work, the study analyzes the actions and interactions that took place in the technological platforms used by the participants (Moodle, Skype and Facebook). The analysis describes how a group of students organized themselves to work collaboratively in order to develop the project and how their participation and interaction to create a Facebook event fostered opportunities to learn how to use Portuguese.

Keywords: Learning projects. Online teaching. Portuguese as additional language. Collaborative work.

\section{Introdução}

As transformações sociais provocadas pelos crescentes avanços tecnológicos têm impulsionado o surgimento de novas formas de socialização e de relação com o conhecimento, estimulando a ressignificação de paradigmas relacionados às teorias de aprendizagem, incluindo as línguas adicionais ${ }^{1}$. Os suportes tecnológicos de redes sociais funcionam como sistemas operativos que organizam formas de interação entre atores sociais, configurando modelos interativos baseados na lógica de comunicação em redes, a convergência de tecnologias e a colaboração. Esses sistemas se caracterizam pela configuração de espaços de conexão, negociação, criação e coprodução, dinâmicas essas que inspiram novas perspectivas de ensino e possibilidades diversificadas de aprendizagem. $\mathrm{O}$ foco da atividade passa do consumo de informação à produção de conteúdo publicável e acessível por qualquer usuário na Internet (PICITELLI; ADAIME; BINDER, 2010).

A fim de refletir sobre as possibilidades de aprendizagem de línguas adicionais que o meio digital oferece, este trabalho apresenta uma reflexão sobre um projeto de aprendizagem de língua portuguesa como língua adicional (PLA) na modalidade online, com base em uma pesquisa realizada em uma das edições do Curso de Espanhol $e$ Português para Intercâmbio ${ }^{2}$ (WEBBER GONZALEZ, 2015). Ao

${ }^{1} \mathrm{O}$ termo línguas adicionais enfatiza o acréscimo de uma língua a outras que o educando já possua em seu repertório, levando em conta os diversos contextos em que pode ser usada. (Schlatter; Garcez, 2009, p. 127-128).

${ }^{2}$ O Curso de Espanhol-Português para Intercâmbio (Cepi) é resultado de uma iniciativa de cooperação entre três universidades participantes da AUGM 
considerar que a proposta de um projeto de aprendizagem pode suscitar uma situação social em que os participantes se orientam ao trabalho conjunto com propósitos compartilhados, configurando um contexto online favorável à construção de conhecimentos sociolinguísticos e culturais relevantes para os participantes, buscamos identificar os momentos em que os participantes trabalharam conjuntamente, analisando como eles se organizaram, os elementos que favoreceram o trabalho colaborativo e as oportunidades de aprendizagem que criaram por meio da participação colaborativa.

Iniciamos com a descrição do curso em que se deu a pesquisa, apresentando os objetivos, a fundamentação teórica, a organização, o conteúdo, e a metodologia do Cepi, passando à apresentação dos conceitos chave que fundamentaram a análise do desenvolvimento do projeto colaborativo. Em seguida, explicamos os procedimentos metodológicos e os critérios utilizados para a identificação das situações em que os participantes se orientaram para o trabalho conjunto. Na seção de análise de dados, identificamos os aspectos que favoreceram o trabalho conjunto e discutimos as oportunidades de aprendizagem que se configuraram ao longo do desenvolvimento do projeto. Ao final, sintetizamos as principais conclusões e apresentamos sugestões para potencializar o engajamento dos participantes no trabalho colaborativo, o uso do português e a construção de conhecimentos sobre a língua adicional.

(Universidade Nacional de Entre Ríos, Universidade Nacional de Córdoba e Universidade Federal do Rio Grande do Sul), com o objetivo de qualificar o intercâmbio acadêmico no Programa de Mobilidade ESCALA Estudantil. O curso foi construído no período de 2007-2009 para ser ministrado totalmente a distância na plataforma Moodle. Participaram da criação e do design do Cepi: Margarita Hraste (coordenadora geral do projeto/UNER), Margarete Schlatter (coordenação Cepi-Português/UFRGS), Víctor Hugo Sajoza Juric e Viviana Sapia (coordenação CEPI-Espanhol/UNC), Gabriela da Silva Bulla (coordenação de materiais didáticos Cepi-Português/UFRGS), Hebe Gargiulo (coordenação de materiais didáticos Cepi-Espanhol/UNC), María Laura Rodríguez (secretária do projeto/UNER). Formaram parte da equipe de técnicos de informática, web design e EAD: Guadalupe Moreira (UNER), Izadora Netz Sieczkowski (UFRGS), Mario Pizzi (UNC), Jerônimo Visñovezky (UNC), Maximiliano Franco (UNER), Paola Roldán (UNER). Sobre o histórico do projeto, ver Schlatter et al., 2007. 


\section{O CEPI e a perspectiva de aprendizagem colaborativa online}

Pela perspectiva de projetos de aprendizagem de línguas adicionais (SCHLATTER; GARCEZ, 2012) e da concepção de aprendizagem por intermédio da participação colaborativa na atividade de pequenos grupos (STAHL, 2006), o estudo realizado teve como cenário de pesquisa uma das edições do $\mathrm{Cepi}^{3}$, que visa a preparar estudantes selecionados pelo Programa ESCALA Estudantil ${ }^{4}$ para realizar um intercâmbio de um semestre em uma universidade estrangeira latino-americana. O objetivo do curso é antecipar oportunidades de participação linguística, cultural e acadêmica na universidade e no país de destino e criar um contexto a distância para o uso da língua adicional e a resolução conjunta de tarefas diretamente relacionadas ao intercâmbio que os estudantes estão prestes a realizar (SCHLATTER et al., 2009).

O Cepi visa a promover a prática do idioma falado na universidade de destino, de modo que cada uma das instituições conveniadas possa ofertar espanhol aos estudantes de universidades brasileiras e português aos estudantes falantes de espanhol ${ }^{5}$. O programa, os objetivos, as instruções para o desenvolvimento do curso $^{6}$, os conteúdos, as tarefas e os exercícios são apresentados

${ }^{3}$ Para conhecer o projeto do Curso de Espanhol e Português para Intercâmbio (Cepi), conferir Schlatter et al. (2007). Para conhecer o histórico sobre as edições do Cepi de 2011.1 a 2013.2, conferir Gargiulo; Bulla; Schlatter (2013).

${ }^{4}$ O Programa ESCALA Estudantil (PEE) promove a mobilidade de estudantes de graduação entre as instituições que compõem a Associação de Universidades do Grupo Montevidéu (AUGM). Para mais informações, acesse: $\mathrm{http} / /$ grupomontevideo.org/sitio/

5 Até o presente momento, o Cepi-Português é oferecido pela UFRGS e o CEPI-Espanhol pela UNC e pela UNER. A proposta do curso é que cada instituição participante da AUGM possa customizar os materiais a partir de textos que tratem de cada universidade e local de destino. Para mais informações sobre o Cepi, acesse: https://www.ufrgs.br/cepi/

${ }^{6}$ O Manual do Aluno (BONOTTO; BULLA, 2011) contém instruções para o manejo das ferramentas e aproveitamento do curso. Acessível em: https://www.ufrgs.br/cepi/wp- 
formalmente no ambiente de aprendizagem Moodle. O curso é organizado em unidades temáticas compostas por um conjunto de tarefas $^{7}$ que se apresentam de acordo com as necessidades que vão surgindo, à medida que se aproxima a data do deslocamento geográfico dos estudantes. As atividades permitem conhecer a cidade e a universidade, preparar-se para os trâmites administrativos e burocráticos da chegada no país, conhecer o currículo e o programa das disciplinas que irá cursar, familiarizar-se com possibilidades de moradia, de alimentação, de localização, além das atividades acadêmicas e de lazer. (SCHLATTER et al., 2007; SCHLATTER et al., 2009).

Na Unidade 1. Nos conhecendo, as tarefas se referem à integração dos participantes no curso: o acesso ao ambiente Moodle e a exploração das ferramentas tecnológicas, a apresentação dos participantes e a constituição do grupo, além de atividades que tratam da importância do intercâmbio para os estudantes. A Unidade 2. Chegando na Universidade proporciona atividades para conhecer a cidade e a universidade de destino, as possibilidades de lazer e as alternativas de moradia, de alimentação e, inclusive, os trâmites legais e acadêmicos necessários para os estudantes estrangeiros. Na Unidade 3. Planejando os estudos, os participantes são orientados a explorar o currículo do curso, entrar em contato com o orientador, planejar as atividades acadêmicas na universidade e as atividades de lazer para realizar com os colegas na cidade de destino.

O Cepi se fundamenta nas concepções de uso da linguagem como forma de ação social (CLARK, 2000), do conhecimento construído socialmente através das interações sociais que acontecem por intermédio da linguagem (VYGOTSKY, 1984) e de gêneros do discurso como orientadores da participação social (BAKHTIN, 2003). $\mathrm{O}$ design do curso prevê a formação de uma comunidade colaborativa

content/uploads/2015/11/Bonotto_Bulla_2011_Manual-Cepi-UFRGS-002final.pdf

7 Tarefas são consideradas como propostas de ações a serem realizadas pelos participantes, tendo em vista os objetivos pedagógicos do curso, já as atividades são entendidas como um conjunto de ações dos participantes executadas conforme proposto em uma determinada tarefa (SCHLATTER et al., 2009). 
de aprendizagem online, entendida como "um grupo de pessoas com diferentes relações sociais e práticas de uso de linguagem em comum e que conseguem construir contextos colaborativos de aprendizagem" (SCHLATTER et al., 2009, p. 7). Os contextos colaborativos são aqueles em que existe uma orientação dos participantes para a participação e em que os participantes são legitimados a engajar-se e contribuir nas produções do grupo (BULLA, 2007).

A comunidade de aprendizagem, no Cepi, forma-se quando os participantes se orientam para o desenvolvimento de práticas de uso da língua adicional respondendo a necessidades e interesses afins, tendo em vista a construção de uma cultura compartilhada, baseada na colaboração e em propósitos comuns. Em uma comunidade de aprendizagem de uma língua adicional, as atividades discursivas dos participantes ao mesmo tempo constroem a comunidade como são foco de estudo, de maneira que se torna necessário criar situações em que a colaboração possa ser fomentada por interações entre os participantes sobre questões significativas para os propósitos do grupo (LEMOS, 2014).

No Cepi, a ampliação da participação em práticas de linguagem do contexto de intercâmbio equivale ao objetivo de ensino e também ao objeto de conhecimento compartilhado e construído em grupo. Busca-se criar oportunidades para que essas práticas de linguagem aconteçam nas interações entre os participantes, por intermédio do uso de suportes tecnológicos de redes - como o próprio ambiente de aprendizagem, a ferramenta Skype e a rede social Facebook - e possibilitem a construção de vínculos entre eles para a formação do grupo. Dessa maneira, a meta é que a comunidade se constitua como contexto social e infraestrutura tecnológica para o trabalho colaborativo online, os suportes tecnológicos atuem como promotores e potencializadores da interação e da aprendizagem entre os membros (COLL; BUSTOS; ENGEL, 2007).

Durante a edição do Cepi-Português UFRGS, além das atividades no Moodle Cepi e no Skype, os participantes formaram um grupo fechado no Facebook, onde realizaram atividades interativas espontâneas. Quando a comunidade de aprendizagem estava formada, as professoras propuseram a realização de um projeto colaborativo de criação e um evento visando a um encontro presencial dos alunos ao chegarem na cidade de destino do intercâmbio. As atividades 
desencadeadas pelos participantes a partir da proposta do projeto foram analisadas em Webber Gonzalez (2015). Neste estudo, apresentamos uma síntese da análise das oportunidades de aprendizagem da língua adicional pela participação colaborativa, configurada no desenvolvimento do projeto durante essa edição do curso.

\section{$3 \quad$ projeto de aprendizagem de língua adicional e o trabalho colaborativo}

A aprendizagem colaborativa é planejada no Cepi tanto na concepção dos materiais didáticos quanto nas práticas pedagógicas (BULLA, 2014), de maneira que uma das metas mais importantes é a configuração de contextos propícios para o engajamento em atividades colaborativas, ainda que os participantes estejam localizados em lugares geograficamente distantes. Assim, um projeto de aprendizagem tem por objetivo mobilizar a participação em ações conjuntas, o que implica a existência de um grupo de pessoas que compartilham o propósito de construção de um produto final, correspondente a um gênero do discurso circulante nos meios pelos quais os participantes materializam sua participação social, nas esferas e nos contextos onde pretendem atuar (ANDRIGHETTI, 2012).

Para Dillenbourg (1999), a aprendizagem colaborativa está relacionada a uma situação em que os pares realizam atividades complementares, trabalhando juntos em função de objetivos compartilhados, propiciando, assim, condições favoráveis ao desenvolvimento de determinadas habilidades e à construção de conhecimentos. De acordo com Roschelle e Teasley (1995), a aprendizagem em contexto colaborativo corresponde a uma atividade síncrona, coordenada e continuada de construção e manutenção de entendimentos compartilhados a respeito da tarefa e dos conhecimentos necessários para levar adiante o empreendimento compartilhado.

Johnson e Johnson (1994) destacam que uma situação de colaboração envolve interação com o propósito de negociação dos aspectos envolvidos em cada etapa do trabalho. A interação produtiva acontece quando os integrantes do grupo assumem o compromisso com os demais e com os objetivos compartilhados, engajando-se nas 
atividades necessárias para manter ou ajustar os propósitos compartilhados. Esse processo implica a realização de tarefas equivalentes e complementares, estabelecendo relações de interdependências colaborativas entre os participantes (RODRÍGUEZ ILLERA, 2001).

A aprendizagem colaborativa, de acordo com Stahl, Koschmann e Suthers (2010), é um resultado possível da construção de entendimentos compartilhados, que tem lugar na interação. Para esses autores, como os processos envolvidos na aprendizagem, tanto em situações individuais como em situações colaborativas, são de difícil acesso para a análise, talvez seja preferível denominá-los de construção colaborativa do conhecimento, em vez de aprendizagem colaborativa. Garcez, Frank e Kanitz (2012, p. 223) explicam a construção conjunta do conhecimento como sequências interacionais em que os participantes constroem "um mundo em comum, removendo obstáculos para tanto se necessário" e, "mediante participação e engajamento", (re)produzem conhecimento compartilhado coletivamente.

A colaboração envolve indivíduos como integrantes de um grupo, compartilhamento de conhecimentos e recursos e negociação de significados (STAHL; KOSCHMANN; SUTHERS, 2010). O trabalho colaborativo pode ser organizado a partir de uma proposta de produção coletiva do grupo, ou seja, de um projeto que envolva: os participantes em um processo de construção e de manutenção de concepções compartilhadas; a realização através de processos grupais e a construção da cultura de colaboração que permeia as atividades do grupo.

Um projeto de aprendizagem de língua adicional pode ser concebido como uma "proposta de produção conjunta" que vincula os objetivos de ensino e de aprendizagem e os objetivos do próprio grupo à construção de um produto que possibilita a participação social efetiva dos integrantes (SCHLATTER; GARCEZ, 2012, p. 90). Em um projeto pensado para a aprendizagem de uma língua adicional, o objetivo compartilhado concretiza-se em um produto final com um propósito social (BRASIL, 1998), por exemplo, a produção conjunta de um texto a partir do qual os participantes podem efetivamente participar no mundo e construir ou ampliar conhecimentos concomitantemente. 
Propor um produto como finalidade de um projeto de aprendizagem possibilita aos integrantes engajar-se na produção coletiva, contemplar os resultados do seu empenho e tornar mais visível a trajetória de aprendizagem, tornando-a mais significativa (ANDRIGHETTI, 2012, p. 73). A construção dos conhecimentos necessários para essa produção envolve "criar recursos de interlocução para construir” (GARCEZ; FRANK; KANITZ, 2012, p. 223) os artefatos compartilhados de linguagem, de maneira que um projeto multiplica as possibilidades de interação produtiva (JOHNSON e JOHNSON, 1999) contextualizada e focalizada na construção do produto compartilhado. As interações em torno do projeto podem configurar momentos propícios para a construção de conhecimentos e o desenvolvimento do uso da língua adicional.

Projetos de aprendizagem envolvem atividades discursivas e mecanismos que ocorrem mais frequentemente em situações colaborativas (apresentação de ideias, sugestões, explicitações, acordos, refutações, ajustes, etc.) que podem favorecer a expansão de recursos linguístico-discursivos. A atividade em torno dos gêneros envolvidos em um projeto de aprendizagem de português no Cepi proporciona a participação em contextos discursivos nessa língua. Um projeto com a meta de produzir discursos para engajar-se em contextos relacionados ao intercâmbio acadêmico em uma universidade brasileira pode ampliar a participação dos aprendizes pelo uso da língua alvo, neste caso, o português. $E$ isso possibilita a construção de aprendizagens que proporcionam autoconhecimento, letramento ${ }^{8} \mathrm{e}$ conhecimentos sobre o mundo (SCHLATTER; GARCEZ, 2012).

No Cepi, um projeto de aprendizagem de língua adicional pode significar a possibilidade de participar na construção conjunta de um produto que vise a inserção e a circulação dos participantes no contexto social do intercâmbio acadêmico, como conhecer os colegas, a universidade e a cidade de destino. Essa produção envolve a

${ }^{8}$ Letramento pode ser entendido como "o estado ou condição de quem exerce as práticas sociais de leitura e de escrita, de quem participa de eventos em que a escrita é parte integrante da interação" (SOARES, 2002, p. 145). Em contextos online, o letramento envolve, além da escrita, uma multiplicidade de culturas, linguagens e semioses, seguindo a lógica de hipertextos e hipermídia (ROJO, 2012). 
construção de práticas compartilhadas de linguagem, por meio de atividades possibilitadas pelas ferramentas tecnológicas online utilizadas, oportunizando a divulgação de conhecimentos contextualizados pelo uso crescente da língua adicional.

\section{Metodologia para a análise do projeto colaborativo online}

A fim de desenvolver um projeto de aprendizagem de língua adicional no Cepi, os participantes tendem a utilizar a língua alvo, em alguma medida, como eixo mediador de todo processo, já que as fontes de informação necessárias se encontram principalmente na língua adicional, favorecendo a utilização de recursos linguístico-discursivos e a realização de interações nessa língua. Este estudo tem como pressuposto que a proposta de um projeto envolvendo gêneros do discurso relevantes aos participantes pode suscitar uma situação social em que eles se orientam ao trabalho em grupo e com propósitos compartilhados, configurando um contexto favorável à construção conjunta de conhecimentos sociolinguísticos e culturais significativos (WEBBER GONZALEZ, 2015).

A edição do Cepi - Português UFRGS tomada como base para o estudo ocorreu durante os meses de janeiro e fevereiro de 2014, em aproximadamente 50 horas, divididas em cinco semanas de curso. Nessa edição, foi proposto o Projeto Eventos no Facebook, que envolveu os participantes na organização de um encontro presencial do Cepi e a produção do convite no formato evento no Facebook. Participaram quinze estudantes de graduação de universidades da Argentina, Chile, Colômbia, México e Paraguai. A equipe pedagógica envolvidos no curso era formada por duas estudantes de Letras da universidade anfitriã, vinculadas ao Programa de Português para Estrangeiros ${ }^{9}$, ambas trabalhando em docência compartilhada no curso,

9 Criado em 1993, o Programa de Português para Estrangeiros (PPE) da UFRGS oferta cursos presenciais de português, o curso de português online CEPI, formação continuada de professores de PLA e desenvolve pesquisa na área de ensino, aprendizagem, elaboração de materiais didáticos e avaliação em PLA. Sobre as atividades desenvolvidas no PPE/UFRGS, ver http://www.ufrgs.br/ppe. 
e a orientadora pedagógica do curso ${ }^{10}$. Os nomes dos participantes e das professoras foram substituídos por pseudônimos. Da mesma maneira, as imagens dos perfis foram desfocadas, a fim de preservar as identidades deles.

A fim de realizar o projeto, os participantes se organizaram em três grupos de trabalho. Os integrantes de cada grupo construíram seus textos no aplicativo eventos do Facebook, convidando os colegas do Cepi para reunir-se quando os participantes já se encontrassem na cidade de destino do intercâmbio, ou seja, em Porto Alegre. Os eventos produzidos pelos grupos foram denominados por eles como Passeio do Cepi em Porto Alegre, Passeio ao Parque da Redenção e Estrangeiros comendo bolo no Gasômetro. Este artigo focaliza a construção de um desses eventos (Estrangeiros comendo bolo no Gasômetro), que foi selecionado por ser representativo dos resultados apresentados por Webber-Gonzalez (2015) em relação às interações dos participantes para a produção do evento proposto.

O Projeto Eventos no Facebook foi proposto pelas professoras aos participantes do CEPI durante um dos encontros via Skype, antecipando as tarefas especificamente pensadas para auxiliar os integrantes dos grupos a organizarem o evento. Essas tarefas foram apresentadas no ambiente Moodle Cepi, na Unidade 2 Chegando na Universidade, na seção A cidade de destino. A tarefa 10. A tarefa Pesquisa sobre Porto Alegre propôs a exploração de sites contendo informações sobre a cidade de destino, lugares turísticos e atividades de lazer, e a tarefa Criando um evento no facebook indicou os passos para a criação de um evento no aplicativo proporcionado pelo suporte da rede social Facebook, orientando a construção e a introdução das informações necessárias para atrair os participantes em potencial.

$\mathrm{O}$ estudo sobre o desenvolvimento do Projeto Eventos no Facebook (WEBBER GONZALEZ, 2015) identificou as situações em que os participantes trabalharam conjuntamente em função de objetivos compartilhados, buscando a compreensão da forma de

\footnotetext{
${ }^{10}$ Para propiciar a formação de professores, o Cepi-Português UFRGS é ministrado em docência compartilhada, em geral, com a participação de dois professores com maior e menor experiência no ensino de PLA e/ou no ensino a distância. Para uma análise sobre a formação de professores por meio de docência compartilhada, ver Lemos (2014).
} 
organização dessas situações quanto à construção de objetivos compartilhados, os modos de participação e organização do trabalho, a utilização dos suportes tecnológicos e o uso da linguagem. A análise possibilitou a identificação dos elementos que constituíram ou favoreceram o trabalho colaborativo, bem como as relações de interdependências entre os participantes e os momentos propícios para a construção de conhecimentos a respeito da língua adicional através da participação colaborativa.

A geração dos dados partiu do registro das ações e interações realizadas pelos participantes nas plataformas tecnológicas utilizadas (Moodle, Skype, Facebook). Foram analisadas as tarefas propostas no ambiente Moodle Cepi, as atividades realizadas pelos participantes nesse ambiente, as interações dos participantes nos encontros virtuais semanais via Skype, durante os quais os grupos construíram as negociações pertinentes ao projeto, e as ações dos participantes no Facebook. O conjunto desses dados possibilitou a análise do processo de construção do produto pelos grupos de trabalho. Também foram consideradas as observações contidas no diário docente, um documento compartilhado no Google Drive no qual as professoras registraram suas percepções durante o desenvolvimento do projeto de aprendizagem.

A partir da observação sistemática do conjunto amplo de dados, foram selecionadas as ações e interações em que os participantes se orientaram para o desenvolvimento do projeto, que ficaram registradas nos suportes do ambiente de aprendizagem Moodle, da ferramenta Skype e da rede social Facebook. Uma análise mais detalhada concentrou a atenção no conteúdo das interações que ocorreram durante os encontros virtuais do Skype, verificando a configuração das situações colaborativas e sua relação com: os objetivos compartilhados; a participação e a organização do trabalho; o uso das ferramentas tecnológicas; a linguagem utilizada e desenvolvida pelos participantes (HEWITT, 2004).

Visto que as atividades dos participantes permaneceram registradas nas plataformas tecnológicas utilizadas, os suportes tecnológicos possibilitaram o acesso ao modo como os significados foram construídos discursivamente (STAHL; KOSCHMANN; SUTHERS, 2010). Esta análise focaliza um excerto das negociações realizadas pelos participantes no desenvolvimento do projeto durante 
os encontros virtuais via Skype. Esses encontros foram gravados em arquivos de MP4, totalizando dez horas de vídeo. Após visualização continuada, foram segmentados os momentos em que os participantes se orientaram para o trabalho, e esses excertos foram transcritos para facilitar a análise da relação entre o conteúdo das negociações e a construção do produto final.

Com base na análise dos dados de interação no Skype, foi possível identificar os momentos em que os participantes configuraram situações de trabalho colaborativo (DILLENBOUG, 1994) e construíram relações de interdependência colaborativa (JOHNSON; JOHNSON, 1999; RODRÍGUEZ ILLERA, 2001). A análise das interações procurou identificar também as oportunidades criadas conjuntamente para a aprendizagem do uso da língua adicional através da participação colaborativa na produção do evento.

O dado que será discutido na próxima seção ocorre no terceiro encontro no Skype realizado pelo grupo que construiu o evento Estrangeiros comendo bolo no Gasômetro. Os registros desse encontro remetem a negociações que se realizaram ao longo do desenvolvimento do projeto, já que, para concretizar a produção do evento no aplicativo, os participantes retomaram as questões negociadas nos encontros anteriores e procederam à criação do evento. Discutiremos como as negociações realizadas durante o referido encontro constituíram momentos em que os participantes trabalharam juntos, configurando situações propícias para a aprendizagem.

\section{A organização da situação colaborativa e as oportunidades de aprendizagem}

A fim de realizar as tarefas que demandam interação síncrona, os integrantes dos grupos de trabalho reuniram-se semanalmente através do Skype. Durante o primeiro encontro virtual, as professoras do Cepi apresentaram a proposta do projeto Eventos no Facebook, abrindo espaço para a negociação da viabilidade e relevância de participação do grupo na organização e na produção de um evento que proporcionasse um encontro para conhecer pessoalmente os colegas do Cepi, quando todos já tivessem chegado a Porto Alegre. Nesse encontro, os participantes trocaram ideias sobre os tipos de lugares que 
poderiam conhecer juntos e as atividades que gostariam de realizar, por exemplo, um passeio em algum lugar caracterizado por belezas naturais.

Durante o segundo encontro no Skype, os participantes se orientaram ao desenvolvimento do projeto, negociando os aspectos relacionados à organização do encontro presencial do Cepi, como local, data, interlocutores e aspectos que poderiam interessar aos convidados. Durante o segundo encontro realizado pelos integrantes do grupo selecionado para a presente análise, os participantes decidiram o local do evento (Usina do Gasômetro), combinaram a data aproximada, definiram como convidados os próprios colegas do Cepi e consideraram, como atrativo de participação no evento, a possibilidade de conhecerem pessoalmente os colegas e, assim, contar com um grupo de amigos durante o intercâmbio no Brasil.

Durante o terceiro encontro do grupo no Skype, os participantes retomaram as negociações sobre a organização do encontro presencial do Cepi, confirmaram a Usina do Gasômetro como lugar do encontro e alteraram a data para que todos chegassem à cidade de destino a tempo de participar do evento. O nome do evento foi finalmente definido, e os argumentos para atrair a participação dos convidados passaram a incluir a perspectiva de conhecer um lugar turístico de Porto Alegre, ver o famoso pôr-do-sol às margens do Guaíba, tomar mate e comer o bolo preparado pelos organizadores do encontro.

O Quadro 1 apresenta um trecho da interação ocorrida durante o terceiro encontro virtual do grupo, durante o qual os participantes produziram o evento Estrangeiros comendo bolo no Gasômetro. Observando o conteúdo do trecho compreendido entre as linhas 256 e $\mathrm{F}^{11}$, pode-se inferir que os participantes, orientando-se à renegociação dos aspectos envolvidos na produção do evento, engajaram-se no trabalho conjunto, organizando as tarefas e funções durante a situação

${ }^{11}$ As linhas numeradas correspondem às falas dos participantes e as linhas identificadas por letras do alfabeto representam as contribuições realizadas por escrito na interface do chat. 
comunicativa por meio da negociação em torno da produção do evento, seguindo as perguntas orientadoras de Ticiane ${ }^{12}$.

\section{Quadro 1: Produção do evento Estrangeiros comendo bolo no Gasômetro}

\begin{tabular}{|c|c|c|c|}
\hline \multicolumn{4}{|c|}{$\begin{array}{l}\text { [Do início do encontro até a fala } 255 \text {, os integrantes do grupo retomaram as negociações realizadas nos encontros } \\
\text { anteriores, sobre os dados do evento, como a data e local do encontro, objetivos e atrativos para a participação.] }\end{array}$} \\
\hline 256 & $25: 18$ & Ticiane: & e então, Hernán? que parte estamos do evento? \\
\hline 257 & $25: 23$ & Hernán: & hay una parte de expansión? \\
\hline 258 & $25: 26$ & Ticiane: & $\begin{array}{l}\text { a parte mais complicada, vocês querem ajudar, Cari e Naomi? de repente vocês podem ir } \\
\text { escrevendo as informações aqui embaixo para o Hernán colocar }\end{array}$ \\
\hline 259 & $25: 56$ & Naomi: & [INAUDÍVEL] para dizer um bolo feito pelo, pela gente, ou outra forma de dizer \\
\hline 260 & $27: 23$ & Ticiane: & bolo caseiro? \\
\hline E & $27: 23$ & Carina: & $\begin{array}{l}\text { Uma reunião muito legal para conocer a gente, conversar, comer o bolo e conhecer um lugar } \\
\text { importante de Porto Alegre. Vamos ficar até a pôr-do-sol }\end{array}$ \\
\hline 261 & $27: 26$ & Naomi: & não, mas, porque aqui somos nós que vai fazer \\
\hline 262 & $27: 30$ & Ticiane: & $\begin{array}{l}\text { é, normalmente bolo caseiro significa que não é industrial, não sei se é isso, bolo feito por } \\
\text { nós? }\end{array}$ \\
\hline 263 & $27: 43$ & Melissa: & é, ou pela gente \\
\hline 264 & $28: 22$ & Ticiane: & $\begin{array}{l}\text { e aí, quando o evento estiver pronto, eu e a Melissa damos sugestões para a escrita do } \\
\text { texto, pode ser? }\end{array}$ \\
\hline $\mathrm{F}$ & $28: 30$ & Naomi & $\begin{array}{l}\text { conhecido como o lugar mais famoso para ver o pôr-do-sol, a gente quer convidar vocês } \\
\text { para tomar uns mates, nos conhecer melhor e comer um bolo feito por nós. Vai ser um } \\
\text { espaco para nos conhecer e conhecer outras culturas }\end{array}$ \\
\hline
\end{tabular}

Fonte: Transcrição de encontro via Skype (WEBBER GONZALEZ, 2015, p. 122)

No trecho transcrito, Ticiane pergunta em que etapa de criação do evento o grupo se encontra (linha 256), dirigindo-se a Hernán, que estava ocupado com a abertura do evento no Facebook naquele momento. Hernán pergunta se há uma parte de expansão na produção do evento (linha 257), gerando uma oportunidade de aprendizagem a respeito da construção do gênero evento no suporte correspondente. Ticiane afirma que se trata da parte mais complicada, convidando as demais integrantes a colaborar com Hernán na escrita de um texto (linha 258). Seguindo a sugestão de Ticiane, Carina e Naomi procedem à escrita do texto, de forma que cada uma introduziu espontaneamente

${ }^{12}$ No início do encontro, os participantes sintetizaram as decisões tomadas nos encontros anteriores, quanto às informações sobre o evento e argumentos para atrair a participação dos convidados. Antes do trecho apresentado, Hernán já havia se encarregado de abrir o evento no Facebook. Depois desse trecho, os participantes negociaram a possibilidade de edição do evento, caso fosse necessários ajustes e correções. 
sua contribuição para a composição do convite, utilizando a interface do chat (linhas E e F).

Naomi expressou sua dúvida quanto à forma de referir-se a um bolo que seria preparado pelos próprios organizadores e oferecido aos convidados durante o encontro (linha 259). Essa pergunta provocou uma sequência de negociação envolvendo sugestões de Ticiane (linha 260 e 262), Naomi (linha 261) e Melissa (linha 263). Entre as opções surgidas na interação ("bolo caseiro", "bolo feito por nós" ou "pela gente"), Naomi selecionou o modo de dizer que lhe pareceu melhor sintetizar o efeito de sentido pretendido (linha F), "um bolo feito por nós".

Com base no trecho apresentado, podemos inferir que os integrantes do grupo organizaram suas funções durante a situação interativa, seguindo a orientação de uma participante mais experiente, Ticiane, que ajudou os demais no processo de construção dos entendimentos compartilhados, relacionados à elaboração do produto. Hernán realizou a tarefa de abertura do evento no aplicativo correspondente no Facebook, enquanto Carina e Naomi atuaram como redatoras do convite. A dúvida de Naomi (linha 259) configurou uma oportunidade de aprendizagem por meio de uma negociação de significado. Dessa maneira, a organização do trabalho ocorreu através da participação de todos os integrantes do grupo e de negociações entre os participantes. Essa atividade gerou oportunidades de construção de significados compartilhados para elaborar o texto do convite para o encontro presencial do CEPI, produzir o evento no Facebook e ampliar conhecimentos relacionados ao uso da língua adicional.

A situação que se configurou durante o encontro virtual, representada no trecho de interação observado (Quadro 1) caracterizou-se pela presença de um grupo de pessoas engajadas na realização do projeto. Os participantes realizaram ações interdependentes (DILLENBOURG, 1994; JOHNSON; JOHNSON, 1999), de maneira coordenada e continuada, através de suportes tecnológicos de comunicação síncrona. Durante a negociação, eles estiveram orientados para a construção e a manutenção de significados e entendimentos compartilhados (ROSCHELLE; TEASLEY, 1995; STAHL, 2005) a respeito dos objetivos do grupo e do que eles consideraram relevante para o evento que estavam construindo juntos. Nesse processo, os participantes configuraram entre si relações de 
interdependências colaborativas (RODRÍGUEZ ILLERA, 2001), em torno dos seguintes elementos:

\section{a) Objetivos compartilhados}

O projeto de aprendizagem desencadeou a negociação de significados quanto à organização e produção do evento, já que, a partir da proposta do projeto, os participantes se engajaram em interações e ações para construir conjuntamente o objetivo compartilhado (a organização do encontro do Cepi e a elaboração do convite em forma de evento no Facebook). A construção do produto final representou, para o grupo, um desafio cuja solução dependeu da participação de todos para apresentar sugestões e participar das negociações a respeito da escolha da melhor data e do local para o evento, por exemplo, e realizar as atividades necessárias para criar o convite, como a pesquisa sobre os lugares turísticos, a abertura do evento no Facebook e a própria escrita do convite.

Ao engajarem-se na proposta de produção do evento, os participantes estreitaram os laços e o compromisso entre si, fortalecendo-se como equipe com o objetivo de produzir o evento de seu grupo. Ao serem colocados em situação de definir uma legenda que identificasse o trabalho do grupo, nesse caso, o título do evento (Estrangeiros comendo bolo no Gasômetro), os integrantes negociaram significados em torno da construção de uma identidade compartilhada, identificando a si mesmos como um grupo de estudantes estrangeiros interessados em conhecer o lugar e a cultura de destino e conhecer e compartilhar elementos culturais com os demais estudantes em intercâmbio.

\section{b) Participação e organização do trabalho}

A participação de cada integrante dependeu da ação dos demais, já que a produção do evento representou um desafio que implicou a participação do grupo. As relações colaborativas foram possibilitadas pelo modo horizontal e inclusivo de participação, em que a contribuição de todos foi promovida e legitimada, com vistas à negociação dos diferentes aspectos do trabalho. Os participantes distribuíram as funções durante a negociação, através da interação, 
assumindo a responsabilidade pela realização das atividades, realizando tarefas coordenadas, complementares e trabalhando junto aos demais na construção do produto.

\section{c) Ferramentas}

O uso que os participantes deram aos suportes tecnológicos permitiu que se mantivessem conectados durante o desenvolvimento do projeto e a realização do trabalho. O Skype foi utilizado como suporte tecnológico que permitiu a realização das atividades síncronas de comunicação e de produção e como plataforma de registro das etapas de construção do convite para o evento. Através do uso das funcionalidades de vídeo-chamada e chat, os participantes convergiram em um espaço virtual compartilhado, proporcionado pela ferramenta Skype, no qual se realizaram processos de negociação para a construção do evento e a escrita do convite. O suporte da rede social Facebook proporcionou o espaço de produção e circulação do produto, tornando possível informar aos convidados e participantes em potencial sobre o evento e abrir espaço para a interação, já que os convidados puderam interagir, confirmando sua presença ou comentando sobre o evento.

\section{d) Uso da língua portuguesa}

A língua portuguesa serviu como mediadora das negociações entre os participantes e da construção de significados em torno do projeto. A produção do encontro presencial do Cepi se deu por meio do uso de recursos linguístico-discursivos em português que possibilitaram a interlocução entre os participantes na língua adicional, a construção do texto do convite e a participação social desejada. Por meio da construção de um repertório linguístico-discursivo reconhecível pelo grupo, os participantes puderam organizar o encontro, sugerindo, opinando e decidindo sobre cada aspecto envolvido na produção do evento.

A proposta de construção conjunta do evento no Facebook configurou uma situação comunicativa com propósitos e interlocutores compartilhados pelos integrantes do grupo. Para isso, os participantes negociaram as características do evento, tendo em vista quais seriam os 
objetivos do grupo quanto à realização do encontro presencial do Cepi, quais os propósitos da escrita e para quem seria dirigido o convite. $\mathrm{Na}$ produção do convite, as informações sobre o evento (local, data, horário) e os argumentos para atrair os convidados, como a oportunidade de ver o pôr-do-sol e de comer bolo, foram pensados de maneira a atrair e mobilizar os interlocutores definidos pelo grupo, os colegas do Cepi.

O convite para o encontro presencial do Cepi, produzido com o objetivo de convidar os colegas do curso para participar do evento, teve como suporte de circulação a rede social Facebook, um contexto caracterizado mais pelas formas livres de dizer do que pela estrutura e correção, em que os textos se definem pela diversidade de linguagens e semioses. $\mathrm{O}$ grupo construiu um texto com as características do gênero evento no Facebook, adequado aos interlocutores, ao suporte de circulação e ao meio virtual. Desse modo, o objetivo dos integrantes foi atingido, já que, através produto compartilhado, os convidados foram informados pela rede social, visualizaram e puderam confirmar presença e interagir com os colegas.

A Figura 1 apresenta o produto final produzido (Evento Estrangeiros comendo bolo no Gasômetro) em seu suporte de circulação (Facebook). É possível observar os elementos do gênero: nome do evento (Estrangeiros comendo bolo no Gasômetro); imagem ilustrativa do lugar (Usina do Gasômetro); informações (data, horário, lugar); mapa com a localização do evento (localizador Google); lista de convidados; resposta dos convidados (confirmação de presença); texto materializando os significados construídos pelos participantes por meio da negociação ao longo das interações do grupo a respeito dos elementos considerados relevantes quanto ao encontro presencial do Cepi, como a possibilidade de "conhecer um lugar importante de Porto Alegre", "conversar", "comer bolo" e "compartilhar". 


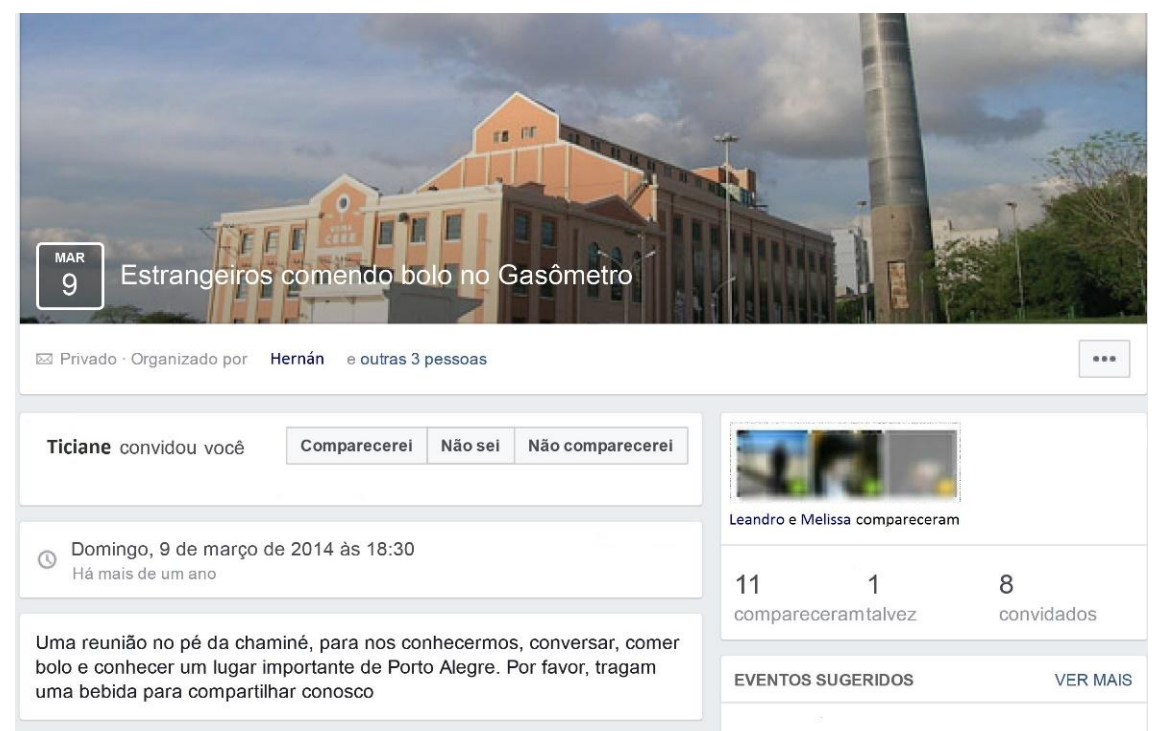

Figura 1: Evento Estrangeiros comendo bolo no Gasômetro

Fonte: Webber Gonzalez, 2015, p. 82

No sistema que se configurou com a proposta do Projeto Eventos no Facebook, os participantes se orientaram para a organização do encontro presencial do Cepi e para a produção do convite em formato de evento no Facebook. Os aspectos que caracterizaram o desenvolvimento do projeto e que podem ter favorecido o trabalho colaborativo foram os seguintes:

- relevância do encontro presencial Cepi;

- objetivo compartilhado (organização do evento do Cepi);

- $\quad$ significados compartilhados sobre o encontro Cepi;

- ações interdependentes e complementares em função de objetivos comuns;

- participação aberta e horizontal, que permitiu a organização localizada;

- uso de ferramentas tecnológicas para a interação e produção conjunta; 
- produção de um gênero com propósitos e interlocutores compartilhados.

Nesse processo, a relevância do encontro presencial Cepi para os estudantes intercambistas foi construída pelo engajamento nas negociações para a efetivação de objetivos compartilhados: a organização de um evento para conhecer e compartilhar com os colegas do Cepi, a realizar-se na chegada à cidade de destino. Os participantes desenvolveram um repertório compartilhado de práticas de uso da língua adicional por intermédio de atividades de leitura, compreensão e produção oral e escrita, realizadas por meio da interação. O repertório linguístico-discursivo incluiu vocabulário, estruturas gramaticais e composição textual relevantes e necessárias para a construção de significados que pudessem materializar o produto final com o propósito e a interlocução projetados.

As ações dos participantes permitiram a participação de todos os membros do grupo, que negociaram atividades e funções na situação de trabalho conjunto. Ao longo das interações construídas conjuntamente, os membros do grupo participaram da organização do trabalho, contribuindo de acordo com as habilidades e recursos de cada integrante e considerando as sugestões de uma participante mais experiente (Ticiane). O uso de um suporte de comunicação síncrona, oral (vídeo-chamada) e escrita (chat), possibilitou a convergência dos participantes em um mesmo espaço virtual, através do qual interagiram entre si para a negociação e a construção dos produtos parciais ${ }^{13}$, como os parágrafos que iriam compor o texto, necessários para a construção do convite virtual.

Quanto às aprendizagens construídas pelos participantes através da participação no trabalho colaborativo, organizado a partir da proposta do projeto, destacamos as oportunidades de desenvolvimento do uso da língua adicional e de conhecimentos a respeito do gênero implicado, além da construção da cultura de colaboração, que permeou as atividades do grupo. Durante o desenvolvimento do projeto, os participantes estiveram envolvidos em situações comunicativas genuínas, gerando a oportunidade de usar a língua portuguesa em

${ }^{13}$ As informações necessárias para a produção do evento, construídas nas negociações orais, foram registradas através da escrita, constituindo uma lista de recursos disponíveis a todos os participantes na tela do chat. 
atividades que envolveram leitura e compreensão para ampliar os conhecimentos sobre a cidade de destino, sobre o próprio grupo e as formas de circulação e produção do gênero eventos no Facebook veiculados em língua portuguesa.

O repertório linguístico-discursivo constituído nas negociações consiste em modos de dizer reconhecíveis nas situações comunicativas envolvidas na realização do projeto e são potencialmente transportáveis a outras situações semelhantes que, provavelmente, os estudantes iriam vivenciar durante o intercâmbio acadêmico. As práticas de linguagem construídas se ajustaram às condições de produção do gênero (propósito comunicativo, interlocutores, formato e suporte), favorecendo a construção de conhecimentos referentes ao gênero implicado, já que os recursos linguístico-discursivos e expressivos foram mobilizados e organizados de modo a obter o efeito de sentido desejado pelos produtores, tendo em vista o perfil dos convidados.

\section{Conclusão}

Neste trabalho, apresentamos o desenvolvimento de um projeto de aprendizagem de português como língua adicional, realizado em uma das edições do curso online Cepi-Português/UFRGS. Refletimos sobre a relação entre a proposta do projeto e a configuração de um contexto propício para o trabalho colaborativo e para a intensificação das possibilidades de aprendizagem da língua adicional através da participação em atividades conjuntas (WEBBER GONZÁLEZ, 2015). O projeto consistiu na organização de um encontro presencial dos alunos do Cepi, na produção de um evento no Facebook e na comunicação através da mesma rede social, configurando uma situação orientada para o trabalho colaborativo que gerou oportunidades de aprendizagem da língua adicional.

Com base na análise das interações ocorridas durante um encontro virtual via Skype, em que os participantes de um dos grupos de trabalho estiveram orientados para a (re)negociação dos detalhes do texto de um convite virtual e para a produção do evento no Facebook, concluímos que a proposta de um projeto colaborativo consiste em uma estratégia condizente com os objetivos de ensino e de 
aprendizagem do Cepi. Isso porque favorece o engajamento dos participantes no trabalho conjunto, potencializando as possibilidades de interação com propósitos genuínos e compartilhados. A situação configurada pelo desenvolvimento de um projeto colaborativo pode oportunizar o desenvolvimento de práticas de uso da língua adicional, a ampliação da participação social por meio do uso dessa língua e a construção de conhecimentos a respeito das formas de circulação e produção do gênero implicado.

O sistema configurado com a proposta do projeto de aprendizagem caracterizou-se pela construção de relações de interdependências colaborativas que se estruturaram de acordo com os objetivos compartilhados. Durante o processo, os participantes se orientaram para o trabalho conjunto, construindo significados em torno da identidade do grupo e do que eles consideraram relevante quanto ao evento no Facebook. A participação na negociação e na organização de tarefas e funções, como sujeito e membro do grupo, possibilitada pelo uso de ferramentas propícias para a comunicação e a produção coletiva do texto, permitiu a convergência dos alunos em um espaço virtual compartilhado, no qual utilizaram espontaneamente a língua adicional como meio de interação e como material para a construção dos recursos necessários para a elaboração conjunta do produto final.

O projeto foi desenvolvido através do trabalho colaborativo, na medida em que configurou uma situação em que membros de um pequeno grupo interagiram entre si, mediados por suportes tecnológicos. Esses alunos orientaram-se para o alcance de objetivos compartilhados, trabalharam juntos durante um determinado ciclo em que organizaram modos de participação e de distribuição do trabalho, além de construírem linguagens e entendimentos compartilhados. Os seguintes aspectos podem ter favorecido o trabalho colaborativo: a relevância do encontro presencial Cepi para os participantes; a construção de um objetivo compartilhado; a estruturação de interdependências colaborativas entre os participantes (negociação, construção conjunta e organização do trabalho); o uso do Skype como suporte de interação e ferramenta produção conjunta; e a construção de um produto final, (gênero evento no Facebook), com propósitos e interlocutores compartilhados.

Ao serem colocados em uma situação de produzir um evento presencial no Facebook, os participantes tiveram que coordenar suas 
posições a fim de definir o propósito do grupo e os interlocutores do convite, construindo relações interdependentes entre eles, que se tornaram responsáveis pela produção de um convite atrativo. Como elemento que atravessou a organização das condições de produção do evento no Facebook, o uso da língua portuguesa esteve estritamente relacionado à construção de significados e práticas compartilhadas. As aprendizagens construídas referem-se ao desenvolvimento do uso da língua portuguesa e de conhecimentos resultantes sobre a produção do gênero implicado.

A mediação da professora Ticiane contribuiu para a construção e a manutenção de entendimentos compartilhados entre os participantes e para a construção das relações de interdependências colaborativas no desenvolvimento do projeto. Como sugestão, algumas estratégias de design poderiam intensificar essas interdependências, por exemplo a inclusão de um desafio adicional que envolvesse a competição entre os grupos. Após produzidos e publicados os eventos, todos os integrantes poderiam participar de uma votação para a escolha do evento mais interessante, o que poderia motivá-los a intensificar os esforços e a colaboração entre os membros, a fim de realizar o melhor trabalho possível.

As seguintes sugestões também poderiam ajudar a incrementar as possibilidades de aprendizagem da língua adicional através da participação colaborativa: a análise de eventos no Facebook favoreceria a construção de conhecimentos a respeito das formas de organização e circulação desse gênero; a inclusão de uma atividade de sistematização dos conhecimentos construídos por meio da participação no desenvolvimento do projeto poderia favorecer a explicitação dos conteúdos mobilizados na participação; o uso de um suporte especificamente pensado para a produção coletiva simultânea, como o Google Drive, poderia mediar a criação e a escrita coletiva do convite.

Um projeto colaborativo de aprendizagem de língua adicional online corresponde a uma proposta de produção colaborativa, na qual os membros se engajam no trabalho conjunto e interdependente, construindo objetivos comuns e concepções compartilhadas sobre o propósito, os interlocutores, o formato e o suporte do produto. Os participantes utilizaram ferramentas tecnológicas digitais para a interação e produção, negociaram o modo de participação e divisão do 
trabalho, desenvolveram práticas compartilhadas de linguagem e interferiram socialmente através de um gênero textual produzido pelo grupo.

\section{Referências}

ANDRIGHETTI, G. H. Reflexões sobre o ensino de português para falantes de outras línguas através da pedagogia de projetos. In: Schoffen et al. (Orgs.) Português como Língua Adicional: reflexões para a prática docente. Porto Alegre: Bem Brasil, 2012. p. 71-90.

BAKHTIN, M. Estética da criação verbal. São Paulo: Martins Fontes, 2003.

BONOTTO, R. C. S.; BULLA, G. S. Manual do aluno CEPI: Curso de Espanhol e Português para Intercâmbio CEPI. 2011.

BRASIL, Ministério da Educação e Cultura, Secretaria de Educação Fundamental. Parâmetros curriculares nacionais: terceiro e quarto ciclos: apresentação dos temas transversais. Brasília: MEC/SEF, 1998.

BULLA, G. S. A realização de atividades pedagógicas colaborativas em sala de aula de português como língua estrangeira. Dissertação (Mestrado em Letras) - Instituto de Letras, Universidade Federal do Rio Grande do Sul, Porto Alegre, 2007.

BULLA, G. S. Relações entre design educacional, atividade e ensino de Português como Língua Adicional em ambientes digitais. Tese (Doutorado em Letras) - Instituto de Letras, Universidade Federal do Rio Grande do Sul, 2014.

CLARK, H. O uso da linguagem. Cadernos de Tradução, n. 9, p. 4971, 2000.

DILLENBOURG, P. What do you mean by collaborative learning? In: Dillenbourg, P. (Ed.). Collaborative-learning: cognitive and computational approaches. Oxford: Elsevier, 1999. p. 1-19. Disponível 
Aprendizagem de Português como Língua Adicional...

em: <http://tecfa.unige.ch/tecfa/publicat/dil-papers-2/Dil.7.1.14.pdf>. Acesso em: 26 nov. 2016.

GARCEZ, P. M.; FRANK, I.; KANITZ, A. Interação social e etnografia: sistematização do conceito de construção conjunta de conhecimento na fala-em-interação de sala de aula. Calidoscópio, v. 10, n. 2, p. 211-224, 2012.

GARGIULO, H.; BULlA, G. S.; SCHLATTER, M. O CEPI como ação de política linguística para o intercâmbio acadêmico. In: VI Encontro Internacional de Investigadores de Políticas Linguísticas, Anais... Porto Alegre, Universidade Federal do Rio Grande do Sul, 2013.

HEWITT, J. An exploration of community in a Knowledge Forum classroom: an activity system analysis. In: BARAB, S.; KLING, R.; GRAY, J. (Eds.). Designing for virtual communities in the service of learning. Cambridge: Cambridge University Press, 2004. p. 210-238.

JOHNSON, R. T.; JOHNSON, D. W. An overview of cooperative learning, 1994 In: Thousand, J. ; Villa, A.; Nevin, A. (Eds). Creativity and collaborative learning. Baltimore: Brookes Press, 1994.

Disponível em:

<http://clearspecs.com/joomla15/downloads/ClearSpecs69V01_Overvi ew\%20of\%20Cooperative\%20Learning.pdf >. Acesso em: 26 nov. 2016.

LEMOS, F. C. A formação do professor para o ensino de língua adicional em ambientes digitais com docência compartilhada. Dissertação (Mestrado em Letras) - Instituto de Letras, Universidade Federal do Rio Grande do Sul, 2014.

PISCITELLI, A., ADAIME, I, BINDER, I., (Orgs.): El proyecto Facebook y la posuniversidad: sistemas operativos sociales y entornos abiertos de aprendizaje. Madrid, Fundación Telefónica, 2010. Disponível em: 
<http://www.fundaciontelefonica.com/arte_cultura/publicacioneslistado/pagina-item-publicaciones/itempubli/4/>. Acesso em: 26 nov. 2016.

RODRÍGUEZ ILLERA, J. L. Aprendizaje colaborativo en entornos virtuales. Anuário de Psicologia, v. 32, n. 2, p. 63-75, 2001. Disponível em:

<http://www.raco.cat/index.php/AnuarioPsicologia/article/viewFile/61 669/88436>. Acesso em: 26 nov. 2016.

ROJO, R.; MOURA, E. (Orgs.) Multiletramentos na escola. São Paulo: Parábola Editorial, 2012.

ROSCHELLE, J.; TEASLEY, S. The construction of shared knowledge in collaborative problem solving. In: O'MALLEY, C. (Org.) Computer supported collaborative learning. Berlin-Heidelberg: Springer., $1995 . \quad$ p. 69-97. Disponível em: <http://tecfa.unige.ch/tecfa/publicat/dil-papers-2/cscl.pdf>. Acesso em: 26 nov. 2016.

SCHLATTER, M.; BULLA, G. S.; GARGIULO, H.; JURIC, V. S. La formación del profesor CEPI para interactuar en una comunidad colaborativa de aprendizaje a distancia. In:II Jornadas Internacionales de Tecnologías Aplicadas a la Enseñanza. Anais... Córdoba: Universidad Nacional de Córdoba, 2009.

SCHLATTER, M.; GARCEZ, P. M. Línguas adicionais na escola: aprendizagens colaborativas em inglês. Erechim, RS: Edelbra, 2012.

SCHLATTER, M.; BULlA, G. S; JURIC, V. S., HRASTE, M., RODRIGUEZ, M. A. A Certificação de Espanhol e Português para o Intercâmbio (CEPI) como uma ação de política linguística no âmbito do Mercosul. In: III Encuentro internacional de investigadores de políticas lingüísticas. Anais... Córdoba: AUGM, 2007.

STAHL, G.; KOSCHMANN, T.; SUTHERS. D. Computer-supported collaborative learning: a historical perspective. In: SAWYER, R. K. (Ed.), Cambridge handbook of the learning sciences .Cambridge: 
Aprendizagem de Português como Língua Adicional...

Cambridge University Press, 2010. p. 409-426. Disponível em: <http://gerrystahl.net/cscl/CSCL_English.pdf>. Acesso em: 26 nov. 2016.

STAHL, G. Group cognition: computer support for building collaborative knowledge. Cambridge, MA: MIT Press, 2006.

VYGOTSKY, L. S. A formação social da mente. São Paulo: Martins Fontes, 1984.

WEBBER-GONZALEZ, N. O trabalho colaborativo online em um projeto de aprendizagem de língua adicional. Dissertação (Mestrado em Letras) - Instituto de Letras, Universidade Federal do Rio Grande do Sul, 2015.

Recebido em: 15/01/2016

Aceito em: 10/04/2016

Title: Learning Portuguese as an Additional Language in a collaborative online project 